[ CONNECTING EMPLOYERS, EDUCATIONAL INSTITUTIONS, AND WORKERS $]$

\title{
Preparing for Careers in Advanced Manufacturing:
}

\section{West Central Ohio Manufacturing Consortium}
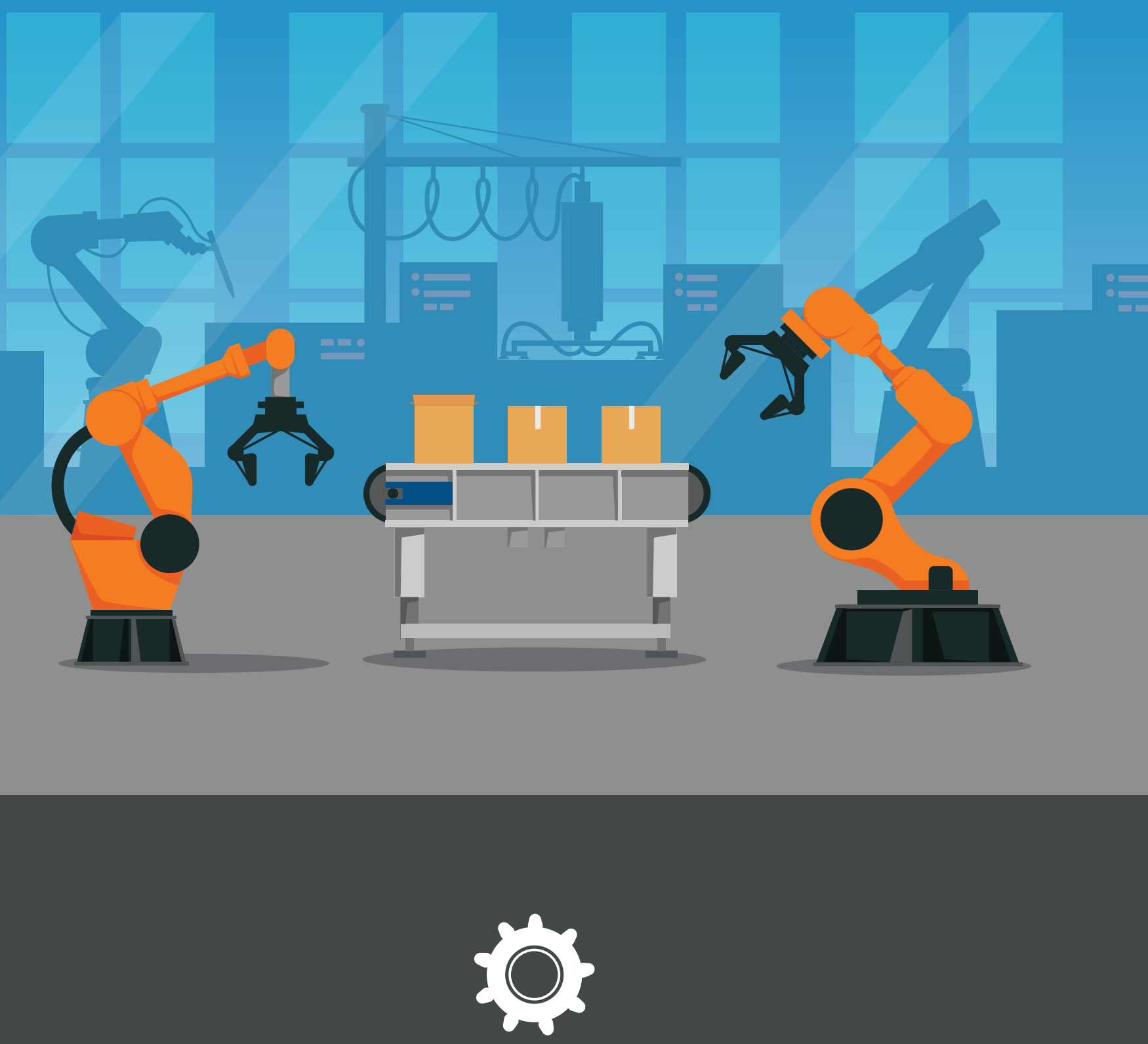

CASE STUDY 3 


\section{Overview}

Manufacturing has a long history in Lima, Ohio, a city of just over 38,000 in the northwestern region of the state. A confluence of rail lines combined with an oil boom in the late 1800s caused the city's population to rapidly expand. ${ }^{1}$ Factories supplying the oil industry as well as a host of other manufactured products moved to the region. The local economy became tied to manufacturing. By the 1930s the oil boom in Ohio faded, ${ }^{2}$ yet manufacturing remained one of the largest employers in Allen County (Lima's home), as well as in the surrounding region (see Figure 1). During the decades between the late 1800s and the present day, the industry underwent major changes. Gone were the dark, dirty, and dangerous factories of the past. Factories became well-lit, spotless, and, beginning in the 1980s, increasingly

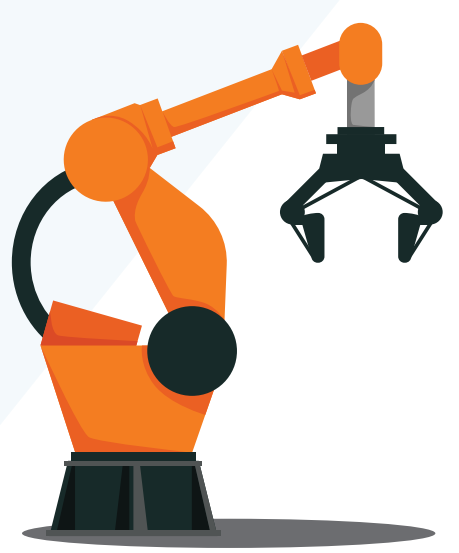
reliant on computer-controlled devices. "This is not your grandfather's manufacturing," commented Amy Odum, the City of Lima's community development director. "This really is clean, fast-paced, challenging, and very rewarding work." 


\section{"The most effective marketing tool is word of mouth- a successful experience is a powerful way to attract more students interested in careers in advanced manufacturing."}

- Rick Turner, director of adult programs, Apollo Career Center

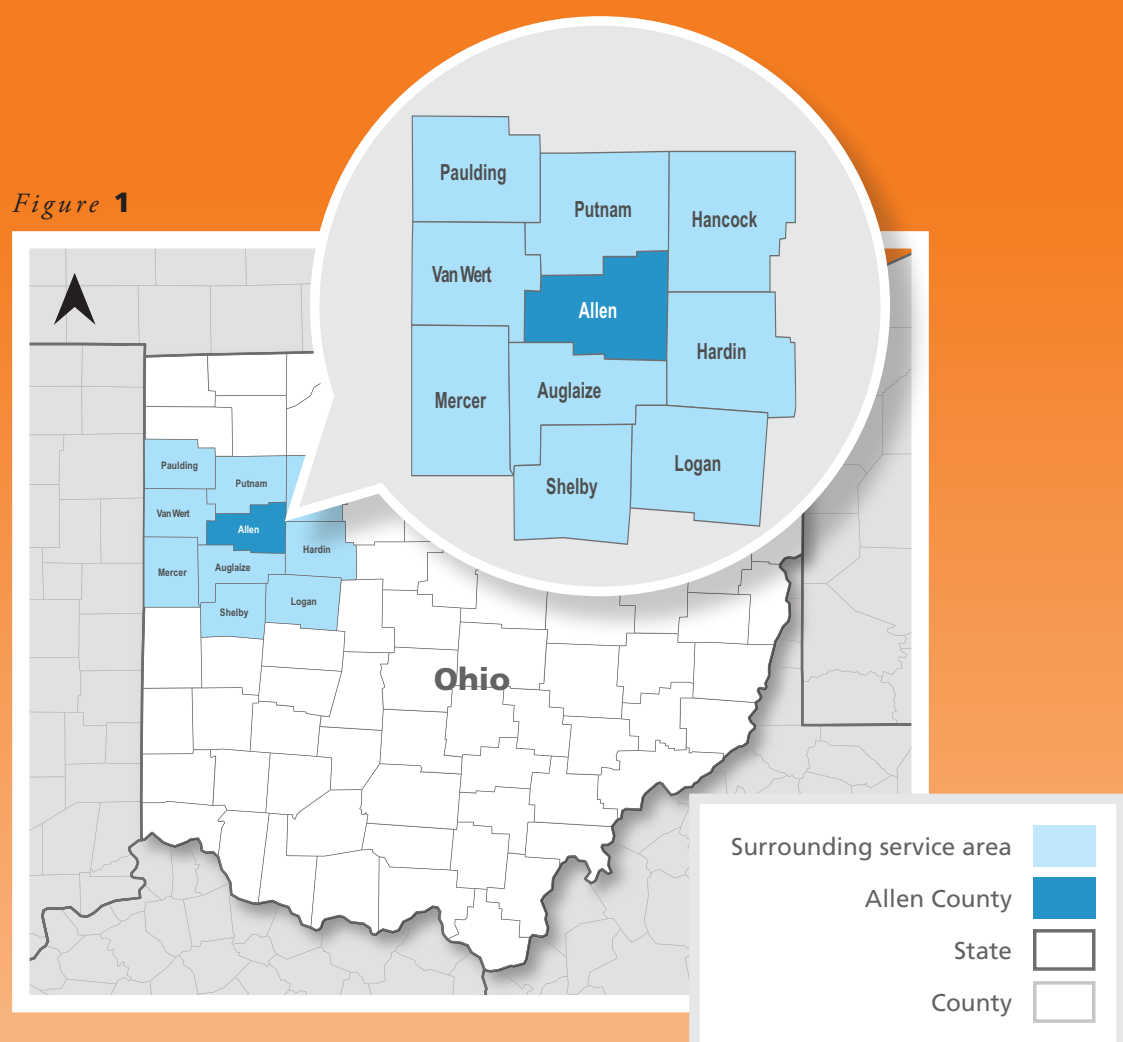

As the workplace environment changed, so did the skill set employers needed. Much of the growth in manufacturing was in positions requiring a higher level of technical skills, and firms complained that job applicants had the wrong skill set. Rhodes State, the local community college, had been hearing about these concerns for some time and, buoyed by grant money, met with local employers and a collection of concerned organizations to survey the region's workforce challenges. The findings from this survey conducted in 2004 and additional conversations with local employers and the City of Lima led to the development of the West Central Ohio Manufacturing Consortium (WCOMC) and its career pathways program in 2005. The WCOMC developed two broad goals: to make the region's manufacturing industry more stable and to remain competitive in order to attract and retain companies.

Following the Great Recession, a new, counterintuitive challenge faced the region. Allen County's unemployment rate at 4.1 percent in September 2015 was lower than both the state's and the nation's ( 4.5 percent and 5.1 percent respectively ${ }^{3}$ ), very positive news for the local economy. Yet, the low unemployment rate also meant a reduced labor pool for job openings. To make matters more difficult, a substantial portion of that pool lacked basic skills, had a spotty employment history, or could not pass a drug test. Building on its strong, long-term relationships among many of its key partners, the WCOMC began working to address that challenge. 


\section{Understanding a Region's Specialization Using Location}

Quotients (2014)

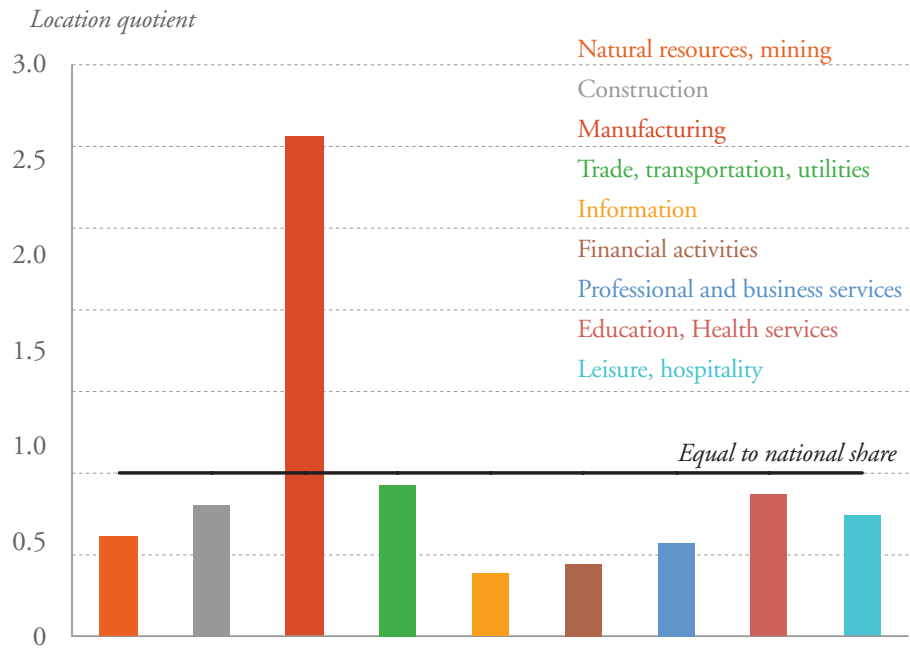

Manufacturing location quotients

\begin{tabular}{l|c}
\multicolumn{1}{c}{ County } & Location quotient \\
\hline Allen & 1.84 \\
\hline Augalize & 4.05 \\
\hline Hancock & 2.83 \\
\hline Hardin & 2.73 \\
\hline Logan & 2.82 \\
\hline Mercer & 3.62 \\
\hline Paulding & 3.59 \\
\hline Putnam & 3.38 \\
\hline Shelby & 4.65 \\
\hline Van Wert & 3.08 \\
\hline
\end{tabular}

Source: Bureau of Labor Statistics.

Note: Values higher than one indicate an industry specialization.

\section{Structure}

The WCOMC operates primarily in Allen County, but some of the participating employers are located in surrounding counties. A brief look at the data makes two things about the region clear:

- The region is rural. While Lima has a population density of 2,820 people per square mile, the remainder of Allen County has only 172 people per square mile. ${ }^{4}$ The surrounding counties average fewer than 100 people per square mile. ${ }^{5}$ In contrast, the state's average is 283 people per square mile.

- Manufacturing is a significant piece of the regional economy. Figure $\mathbf{2}$ illustrates this by using location quotients, a common way to measure industry specialization. Location quotients compare the share of an industry in one region against a larger geographic area, usually the United States. A number greater than 1.0 indicates industry specialization. When looking at manufacturing exclusively, Allen and the surrounding counties all have manufacturing location quotients greater than 1.0. In fact, Shelby County has a location quotient of 4.65 , indicating its share of manufacturing employment is over four times greater than that of the U.S. When looking at location quotients in each major employment sector for the region, manufacturing is the only sector in which shares are greater than the national average.

Prior to the WCOMC's inception, a collection of organizations and institutions began a conversation around the importance of maintaining a stable manufacturing economy and cultivating a competitive regional workforce. They received a grant to survey local manufacturing employers about their long-range growth plans, skill set requirements and gaps, and hiring and retention issues. Results from this survey and further conversations with employers led to a career pathway designed to accomplish three things:

1. Provide a clear pathway for both incumbent and entry-level workers to increase their skill levels in order to advance within their companies or enter the job market with acceptable job skills. 
2. Ensure a qualified workforce can replace the retiring baby boomers who nationally retire at a rate of roughly 10,000 per day. ${ }^{6}$

3. Cultivate a workforce boasting strong skills that can be attractive for companies interested in relocating to or remaining in the region.

The career pathway consists of earnable credentials and certifications related to advanced manufacturing, with multiple entry points depending on the student's level of expertise. The foundational step is the Basic Pathway, a free, 40-hour course designed to give graduates basic knowledge of the manufacturing process, as well as communication, safety, and general workplace skills. The entry-level Basic Pathway course is intended as a way for low-skilled individuals with spotty employment histories to be able to add a foundational credential to their resumes. Since 2005, close to 600 students have earned the Basic Pathway certification.

The WCOMC is made up of a community college, a vocational school, several community organizations, and a collection of employers. Figure $\mathbf{3}$ (see following page) shows a simplified model of the WCOMC's structure. Rhodes State College houses the WCOMC and provides the Basic Pathway class, 2-year associate degrees, a variety of intermediate and advanced certificates, and customized training courses requested by employers. Apollo Career Center is a vocational school serving both high school students and adults and offers intermediate certificates in a variety of advanced manufacturing-related fields. The community organizations are a conduit for students into the Basic Pathway course. Many of their clients are unemployed or lack the skills necessary to attain a job paying a living wage. The final piece is the employers; nearly 30 participate in the WCOMC in a variety of ways. They can provide feedback on the curriculum and make suggestions as their needs change. Employers can also send their workers to Rhodes State and Apollo Career Center to complete additional training to move up the career ladder. Membership dues give the workers access to training, other services, and equipment at Rhodes State College at reduced or no cost.

Engagement with both the community and participating employers is a key activity for the WCOMC. In conjunction with Rhodes State College and Apollo Career Center, the WCOMC works with high schools that have technical programs to inform students of careers in advanced manufacturing. During October, designated as "Manufacturing Month," the WCOMC partners with local employers to arrange factory tours to help dispel stereotypes parents and students may hold of factories being dangerous and career-limiting places to work. The community organizations promote the Basic Pathway course to clients who show interest in advanced manufacturing. Apollo Career Center also promotes its course offerings via print mailings and advertising on social media, radio, and television.

Funding comes from a few sources. The City of Lima provides a portion via Community Development Block Grants (CDBGs). However, one stipulation of using CDBG funds is the money can only be spent on Lima residents who are classified as low- or moderate-income. ${ }^{7}$ Rhodes State matches the city's input through in-kind labor, while additional funding sources support students who live outside of Lima. ${ }^{8}$

One example of how a community-based organization works within the WCOMC is the WORTH Center, a treatment and habilitation center located in Allen County. The WORTH Center houses roughly 100 men and women up to 180 days as an alternative to prison. Many of the residents' offenses relate to drugs or alcohol; in addition, many have spotty work histories and require remedial math and reading classes. The WORTH Center employs a two-stage process. All residents first undergo a 30-day probation period where their needs ranging from physical and emotional to educational are evaluated. During this period they cannot leave the facility. Following that is the transitional period during which they can begin working toward a GED (if necessary), begin the Basic Pathway program (if they show an interest in advanced manufacturing), and become eligible for work release. Basic Pathway courses are taught on-site at the WORTH Center by Rhodes State College staff. Matt Kinkley, executive director of workforce, economic development, and continuing education at Rhodes State College, pointed to a "community activism" element of the community-based organizations' conduit role. "Industry sets the expectations of what they want, and then we're trying through the community-based organizations to help those individuals make that next step." 


\section{West Central Ohio Manufacturing Consortium}

\section{Funding \& Promotion}

\section{City of Lima, Ohio}

- Provides portion of funding for the 40-hour Basic Pathway program via Community Development Block Grants (CDBG)

- Promotes the career pathway program

- Benefits from increased income tax collection as students complete the Basic Pathway program and enter the advanced manufacturing workforce

\section{Students}

Many students in the Basic Pathway program come from community-based organizations such as:

\section{- Lima Allen Council on Community Affairs}

- Western Ohio Regional Treatment and Habilitation (WORTH) Center

- Allen County Department of Job and Family Services

\section{Rhodes State College (founding partner)}

is a community college that houses WCOMC

\section{Apollo Career Center (founding partner)}

is a joint vocational school district that serves both high school and adult students

\section{Employers}

- More than 30 employers take part in the consortium, with 10 participating regularly in WCOMC meetings

- Provide survey input every four years to help WCOMC assess needs and determine whether career pathway adjustments are called for

- Recognize that Basic Pathway graduates are qualified for entry-level positions 


\section{Prompted by input from employers, Rhodes State College and Apollo Career Center developed a shorter 9- to 12-month program in areas such as CNC machinist and programmer and welding and production associate that allows workers to fill open positions and satisfy industry needs faster.}

\section{Successes and obstacles}

Over its 10-year history, the WCOMC has dealt with a variety of challenges and enjoyed numerous successes. The following section will highlight some of each.

\section{PARTNERSHIP \& ENGAGEMENT}

The WCOMC lacks a regional transportation voice.

This was brought up during one of the interviews in response to a question of whether any group was missing from the consortium. The region is rural, and while public transportation is available, it is not always a viable option, particularly when shiftwork is involved.

\section{It can be difficult to recruit and retain students.}

As the economy improves, the pool of potential students shrinks, and it becomes increasingly difficult to decide how best to attract new students and meet the needs of employers. The WCOMC, Rhodes State College, and Apollo Career Center have used a variety of ways to attract students: mailings, radio ads, social media, and outreach visits to high schools. However, according to Rick Turner, the director of adult programs at the Apollo Career Center, the most effective marketing tool is word of mouth-giving students the opportunity to hear about a successful experience is a powerful way to attract more of them to investigate careers in advanced manufacturing. In addition to attracting new students, WCOMC recognizes the need to engage them once they complete the Basic Pathway course. Starting approximately five years ago, the WCOMC began sending students weekly job postings in the two years after they achieved certification as a way of maintaining contact. Apollo Career Center is required to contact students for the first year out. According to Ann Benfield, the industrial training manager at Apollo Career Center, "I like to know where they're employed and how much they make, because then I know where to send prospective students.”

\section{Employer feedback is important to improve} curriculum and coursework offerings. Two examples came up during the interviews pointing to the value of having employers engaged in the consortium. A typical intermediate-level certificate takes 12 to 15 months to complete. Prompted by input from employers, Rhodes State College and Apollo Career Center developed a shorter 9- to 12-month program in areas such as $\mathrm{CNC}$ machinist and programmer and welding and production associate that allows workers to fill open positions and satisfy industry needs faster. Once employed, workers can take the remaining classes to attain full certification. Another local employer expressed an interest in leadership training courses for supervisors, and worked with Rhodes State to develop a program with 25 topic areas to choose from. This enables advanced manufacturing companies to save on travel costs by not having to send employees to classes outside the region. An added benefit is that the course is open to other employers.

\section{Regular communication among partners and the} periodic survey of employers ensure the career pathway remains relevant and allows the WCOMC to adjust its strategy. Each of the community organizations we interviewed mentioned the great value in receiving regular updates, job postings, and minutes from WCOMC meetings-which many reported they are unable to attend regularly in person. Even though virtual, this regular contact keeps WCOMC members engaged and up to date with the program. Another key piece to the WCOMC is the survey of its manufacturing partners conducted every three to four years. Results from the survey allow the WCOMC to reassess its focus and ensure the consortium continues to meet the employers' needs. 
Broad, long-running consortium ensures a strong regional commitment. The WCOMC, in existence for ten years and under development for several years before that, has led to many long-term relationships among a broad coalition of stakeholders representing education, employers, and community organizations. This investment of time creates momentum to carry the program further. According to Doug Durliat, director of the WCOMC, the consortium has played a critical role in ensuring that Rhodes State College remains engaged with the advanced manufacturing industry.

\section{LOCAL ISSUES}

The cyclical nature of manufacturing creates varied demand for labor and can lead to negative feelings about the industry. In the years leading up to the Great Recession (2001-2007), the region's manufacturing employment declined by about 1 percent per year. ${ }^{9}$ During the Great Recession (2007-2009), that decline increased to 9 percent per year, greater than the national rate of 7 percent. However, since the end of the Great Recession (2009-2014), the region's manufacturing employment has rebounded substantially faster than the nation's, growing nearly 3 percent per year instead of 0.4 percent per year for the nation (roughly 6 times greater). This up-and-down cycle manifested in similar patterns of interest (and disinterest) in manufacturing jobs. As Rick Turner from Apollo Career Center noted, "From 1990 through the Great Recession, we struggled with enrollment in manufacturing [programs] because parents said to their kids, 'Oh no, don't do that, go do something else, you'll get laid off, you'll get displaced, they'll move your company out of the country." Now, with the postGreat Recession resurgence in manufacturing employment and Apollo's classes at capacity, the center is embarking on a $\$ 53$ million expansion of its facilities. 
Matt Kinkley, executive director of workforce,

economic development, and continuing education at Rhodes State College,

\section{pointed to a "community activism" element of the community-based organizations' conduit role: "Industry sets the expectations of what they want, and then we're trying through the community-based organizations to help those individuals make that next step."}

\section{Local workforce presents a variety of challenges.}

Nearly everyone we interviewed mentioned difficulties in the regional workforce. Most new hires for manufacturing employment must pass a drug test, for instance; but such a test is a barrier many cannot overcome. Others have no work history or a spotty one that makes crafting a resume difficult. Some lack basic reading and math skills, which are increasingly important in advanced manufacturing positions. Prospective employees have to spend time remediating these skills or risk not qualifying for a position. Felony records are another red flag. Many of the interviewees mentioned the stigma attached to employment candidates' having a criminal history. For example, the WORTH Center finds many companies are instantly turned off by felons, whether because of preconceived notions or because one bad experience has made them step back. Soft skills, which point to abilities in and awareness of things such as communication, personal habits, and interpersonal skills, pose yet another challenge among the workforce. Showing up late to work without calling, not showing up at all, and dressing inappropriately are some manifestations of lacking or poor soft skills, and are a turn-off to employers. Every organization we interviewed mentioned soft skills as a major problem for employers - and a skill set that is particularly difficult to teach. Among those offering them, Jacqueline Fox, the chief executive officer at the Lima Allen Council on Community Affairs, has an in-house sewing program designed to teach soft skills. For practice, students can advance to working in the Head Start classrooms and then on to maintenance and reception duties in the office. At the WORTH Center, students watch videos, take personality tests, and discuss what they learn. But "trying to drive motivation where it doesn't always exist" can be difficult, noted Matt Kinkley from Rhodes State College.

\section{BOTTOM LINE}

The program gets people back to work. What have been the biggest successes for this program? "Getting people back to work so they can provide for their families," said Rick Turner of Apollo Career Center. Nearly everyone interviewed had a similar response to this question. According to Marilyn Horstman, the deputy director of social services at the Allen County Department of Job and Family Services, another benefit is that people need fewer social services once they become employed. And these are good jobs. According to the Bureau of Labor Statistics, the region's manufacturing wage is substantially higher than the region's average annual wage. In Allen County and the surrounding counties, the average annual wage for manufacturing in 2014 was $\$ 54,211$, which is 1.5 times greater than the average wage of all other industries. ${ }^{10}$

\section{Employees want something that is relatively quick to attain and portable between firms, while employers} want to get qualified employees. As Amy Odum from the City of Lima said, "The new understanding is that it has to be flexible, it has to be fast, and it has to be portable." 


\section{Conclusion}

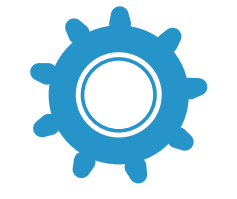

\section{Longstanding partnerships with employees and educational} instututions are key to the WCOMC's helping prepare a trained workforce for the region's advanced manufacturing industry.
"Our goal is very simple yet very, very difficult to achieve," stated Rick Turner from the Apollo Career Center, "and that is to get people who are unemployed or underemployed reskilled, and get them good jobs that serve business and industry in the region." For ten years the WCOMC, a broad-based collection of entities that recognizes the importance of advanced manufacturing to this rural, northwestern Ohio region, has been working toward that goal. Its success is likely a result of a combination of the people involved, the organizations that take part, and the length of time during which relationships have been strengthened. Two educational institutions provide the certifications and classes, a collection of community-based organizations helps funnel students into the program from the most at-risk segments of the population, and the employers act both as hirers and as a "reality check" to ensure that what is being taught in the classroom is of use on the job. Periodic surveys of employers help to ensure the WCOMC continues to adapt to changes in the manufacturing industry.

Persistent challenges the consortium faces include the lack of a transportation voice at the table, WCOMC's ongoing search for ways to attract new students to the program, and overcoming negative perceptions of the manufacturing industry. The longstanding consortium will continue to draw on its strengths - among them the relationships forged among members over time, the continued communication among partnering organizations, and the vital feedback employers provide to help refine and adapt the program curriculum itself-in its continuing efforts to achieve its goal of successfully preparing students for careers in advanced manufacturing and ultimately strengthening the region's economy.

Author Matt Klesta is a Policy Analyst with the Community Development Department at the Federal Reserve Bank of Cleveland. 
Authors: Kyle Fee, Matthew Klesta, and Lisa Nelson, Federal Reserve Bank of Cleveland

Published by the Federal Reserve Bank of Cleveland's Community Development Department.

The views expressed in this publication are those of the authors; these views do not necessarily reflect those of the Federal Reserve Bank of Cleveland, the Federal Reserve Board of Governors, or the Federal Reserve System. Reprinting allowed with permission; contact Managing Editor Anne O'Shaughnessy at Anne.oshaughnessy@clev.frb.org.

Members of the Cleveland Fed Community Development Department include

\section{CLEVELAND}

Paul Kaboth

Vice President \&

Community Development Officer

216.579.2951

Paul.kaboth@clev.frb.org

Mary Helen Petrus

Assistant Vice President

216.579.2443

Mary.h.petrus@clev.frb.org

Brett Barkley

Research Analyst

216.206.3658

Brett.barkley@clev.frb.org

Kyle Fee

Regional Community

Development Advisor

216.579.2029

Kyle.d.fee@clev.frb.org

Matthew Klesta

Policy Analyst

216.579.3166

Matthew.klesta@clev.frb.org

Hal Martin

Policy Economist

216.774.2526

Hal.martin@clev.frb.org

Lisa Nelson

Community Development Advisor

216.579.2903

Lisa.a.nelson@clev.frb.org

Anne O'Shaughnessy

Communications Advisor

216.579.2233

Anne.oshaughnessyww@clev.frb.org

Ann Marie Wiersch

Senior Policy Analyst

216.579.2423

Annmarie.wiersch@clev.frb.org
PITTSBURGH

Joseph Ott

Regional Community

Development Advisor

412.261.7947

Joseph.c.ott@clev.frb.org

CINCINNATI

Bonnie Blankenship

Regional Community

Development Advisor

513.455 .4281

Bonnie.blankenship@clev.frb.org
CONNECT WITH THE CLEVELAND FED

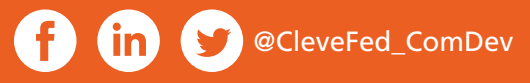


www.clevelandfed.org/communitydevelopment 